\title{
Galangin suppresses human osteosarcoma cells: An exploration of its underlying mechanism
}

\author{
ZHIFAN YANG $^{1 *}$, XIUCHENG LI $^{2 *}$, WEIQI HAN ${ }^{2}$, XUANYUAN LU ${ }^{2}$, \\ SONGTAO JIN ${ }^{2}$, WANLEI YANG ${ }^{2}$, JIANLEI LI ${ }^{2}$, WEI HE ${ }^{2}$ and YU QIAN ${ }^{1,2}$ \\ ${ }^{1}$ The Second Affiliated Hospital and Yuying Children's Hospital of Wenzhou Medical University, \\ Wenzhou, Zhejiang 325027; ${ }^{2}$ Department of Orthopaedics, Shaoxing People's Hospital, \\ Shaoxing Hospital of Zhejiang University, Shaoxing, Zhejiang 312000, P.R. China
}

Received May 30, 2016; Accepted October 24, 2016

DOI: $10.3892 / o r .2016 .5224$

\begin{abstract}
Osteosarcoma is the most common malignant bone tumor that frequently affects adolescents. Osteosarcoma cells tend to proliferate and invade other tissues such as those of the lungs. Currently, neoadjuvant chemotherapy is the primary strategy to prevent tumor progression. However, its adverse effects result in poor long-term outcomes. Previous research has shown that galangin exhibits antitumor properties on several types of cancer cells; however its effect on osteosarcoma cells is yet unknown. The aims of this study were to evaluate the effects of galangin on the proliferation, apoptosis, migration, and invasion of osteosarcoma cells and to explore the underlying mechanisms. We found that the proliferation of MG63 and U20S osteosarcoma cells decreased significantly, while the apoptosis of MG63 cells accelerated significantly after exposure to galangin. In addition, the migration and invasion of MG63 cells were significantly inhibited by galangin. Moreover, phosphoinositide 3-kinase (PI3K) and $\mathrm{Akt}^{\mathrm{p}-\mathrm{Th} 308}$ expression levels were found to be significantly lower in galangintreated MG63 cells than in the control cells, and the protein expression levels of their downstream regulators cyclin D1 and matrix metalloproteinase $2 / 9$ were also downregulated in galangin-treated groups, while those of $\mathrm{p} 27^{\mathrm{Kip} 1}$, caspase- 3 , and caspase- 8 were upregulated. These findings suggest that galangin suppresses osteosarcoma cells by inhibiting their proliferation and invasion and accelerating their apoptosis, and the mechanism may be associated with the inhibition of PI3K and its downstream signaling pathway.
\end{abstract}

Correspondence to: Professor Yu Qian, The Second Affiliated Hospital and Yuying Children's Hospital of Wenzhou Medical University, Wenzhou, Zhejiang 325027, P.R. China

E-mail: doctor120@hotmail.com

${ }^{*}$ Contributed equally

Key words: galangin, osteosarcoma, proliferation, apoptosis, invasion, $\mathrm{PI} 3 \mathrm{~K}$

\section{Introduction}

Osteosarcoma is one of the most common malignant bone tumors. It originates in stromal cell lines and is characterized by rapid growth (1). Nearly $80 \%$ of osteosarcoma cases occur within the age range of 10-20 years, causing extensive damage in the children and adolescents who suffer from the disease (2). Osteosarcoma cells tend toward division and proliferation because of an unregulated cell cycle. Moreover, osteosarcoma usually metastasizes at an early stage. Epidemiological surveys have reported that approximately $40 \%$ of osteosarcoma patients die from early metastasis, especially pulmonary metastasis (3). The prognosis is far from optimistic, with an overall five-year survival rate of $20 \%$ in cases with metastases (4). With improvements in limb salvage operations combined with pre- or post-operative neoadjuvant chemotherapy, the five-year survival rate has increased to approximately $60 \%$ (5). However, the high doses of chemotherapeutics cause toxicity in normal tissues and damage the liver and kidneys. Cellular chemoresistance presents another challenge, limiting the long-term curative effect of chemotherapy $(6,7)$. Thus, safe and effective therapy options for osteosarcoma are urgently needed.

Galangin (3,5,7-trihydroxyflavone, Fig. 1A) is a natural bioflavonoid primarily extracted from the rhizome of Alpinia officinarum, which has been used as an herbal medicine in Asia for decades. Previous studies have showed that galangin has anti-inflammatory $(8,9)$, antibacterial $(10,11)$, and antiviral $(12)$ activities in vitro. Currently, it is in focus for its antitumor property. Studies have shown that galangin suppresses the proliferation and functions of various tumor cells, including renal carcinoma Caki cells (13), hepatocellular carcinoma (14), fibrosarcoma (15), and squamous carcinoma (16). However, the effects of galangin on osteosarcoma are still not clear. The aims of this study were to evaluate the effects of galangin on the proliferation, apoptosis, and invasion of osteosarcoma cell lines in vitro and to explore the underlying mechanism of action.

\section{Materials and methods}

Cell culture. The human osteosarcoma cell lines MG63 and U20S (Cell Bank of the Chinese Academy of Sciences, 
A<smiles>O=c1c(O)c(-c2ccccc2)oc2cc(O)cc(O)c12</smiles>

Galangin

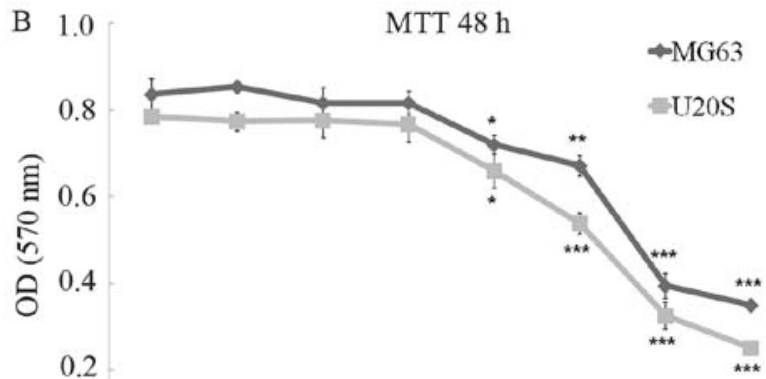

0.2

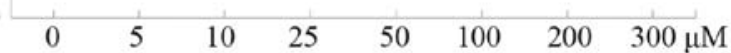

C
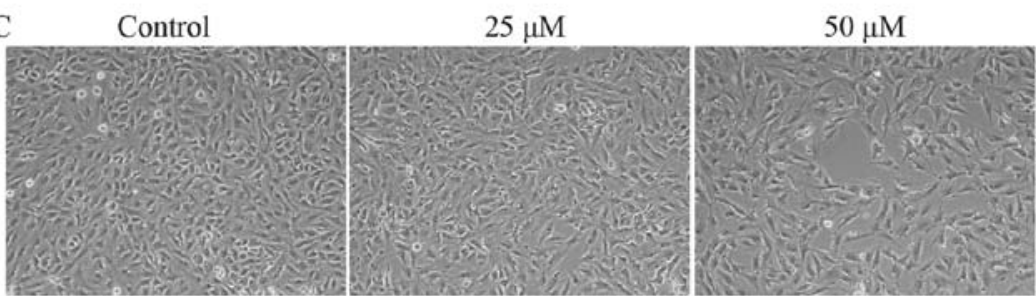

$100 \mu \mathrm{M}$

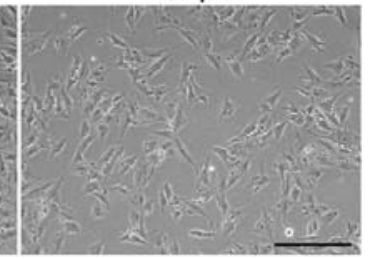

Figure 1. Inhibition of osteosarcoma cell proliferation by galangin. (A) Molecular structure of galangin. (B) MTT assays with MG63 and U20S cells treated with galangin for $48 \mathrm{~h}$ (mean $\pm \mathrm{SD})$. ${ }^{*} \mathrm{P}<0.05,{ }^{* *} \mathrm{P}<0.01$, or ${ }^{* * *} \mathrm{P}<0.001$ versus the control group. (C) Morphological changes in MG63 cells treated with galangin for $48 \mathrm{~h}$, photographed using an inverted phase contrast microscope. Scale bar, $100 \mu \mathrm{m}$.

Shanghai, China) were used in this study. Cells were cultured in Dulbecco's modified Eagle's medium (DMEM), which was supplemented with $10 \%$ fetal bovine serum and $1 \%$ streptomycin-penicillin. Cells were seeded into 96-well plates at a density of $8 \times 10^{3}$ cells/well or 6 -well plates at a density of $1 \times 10^{5}$ cells/well for the following procedures. The morphology of cultured cells was observed with an inverted phase contrast microscope.

Cell proliferation assay. MG63 and U20S cells were treated with galangin at concentrations of $0,5,10,25,50,100,200$, and $300 \mu \mathrm{M}$. After incubation for $48 \mathrm{~h}, 10 \mu \mathrm{l}$ 3-(4,5-dimethylthiazol-2-y1)-2,5-di-phenyltetrazolium bromide (MTT) solution $(5 \mathrm{mg} / \mathrm{ml}$ in PBS) was added to each well. Cells were incubated for another $4 \mathrm{~h}$, and then the medium was replaced with $150 \mu 1$ of dimethyl sulfoxide (DMSO) solution to solubilize the crystals. The results were read at $570 \mathrm{~nm}$. SPSS software version 19.0 was used for calculation of median lethal concentration $\left(\mathrm{LC}_{50}\right)$.

Hoechst 33258 staining. MG63 cells were treated with galangin at concentrations of $0,25,50$, and $100 \mu \mathrm{M}$. After incubation for $24 \mathrm{~h}$, the medium was removed and the cells were fixed with $4 \%$ polyoxymethylene for $20 \mathrm{~min}$ and washed twice. Then, $10 \mu \mathrm{g} / \mathrm{ml}$ Hoechst 33258 solution was added, and the cells were incubated in the dark for $5 \mathrm{~min}$ and then washed three times. The cells were observed under a fluorescence microscope, and those in brilliant blue color were counted.

Flow cytometry. Cell apoptosis was evaluated using Annexin $\mathrm{V}$ fluorescein isothiocyanate and propidium iodide (Annexin V-FITC/PI) apoptosis detection kits (Life Technologies, Waltham, MA, USA). MG63 cells were treated with galangin for $48 \mathrm{~h}$ at concentrations of 0,25 , 50 , and $100 \mu \mathrm{M}$. Then they were harvested and stained with
Annexin V-FITC or PI and were analyzed on a FACScan flow cytometer (Becton, Dickinson, and Company, Franklin Lakes, NJ, USA). Annexin V(+)/PI(-) cells were considered early apoptotic cells, while Annexin $\mathrm{V}(+) / \mathrm{PI}(+)$ cells were considered late apoptotic cells.

Scratch-wound healing assay. MG63 cells were seeded in 6-well plates and cultured to confluence, followed by serum starvation overnight prior to wounding, and treated with galangin at concentrations of $0,25,50$, and $100 \mu \mathrm{M}$ for 24 and $48 \mathrm{~h}$. The wound area was observed under an optical microscope.

Transwell assay. Transwell assays with matrigel were performed to evaluate cell migration and invasion as previously described (17). Briefly, MG63 cells were seeded in the upper surface of Transwell chamber at density of $1 \times 10^{5}$, and treated with galangin for $48 \mathrm{~h}$ at concentrations of $0,25,50$, and $100 \mu \mathrm{M}$. Then cells on the upper parts of chamber were removed, while the invaded cells were fixed, stained and counted under a high-power microscope.

Western blotting. Radio-immunoprecipitation assay (RIPA) lysis buffer was used to extract total cellular protein lysates, which were subjected to electrophoretic separation and transferred to nitrocellulose membranes via electroblotting. Next, the membranes were blocked with 5\% non-fat dry milk for $20 \mathrm{~min}$, and the proteins were probed with primary antibodies overnight at $4^{\circ} \mathrm{C}$. Membranes were washed three times in solution and incubated with horseradish peroxidaseconjugated secondary antibodies (Sigma-Aldrich, St. Louis, MO, USA) for another $2 \mathrm{~h}$. LAS-4000 Science Imaging System (Fujifilm, Tokyo, Japan) was used to observe the protein bands. The following primary antibodies were used: phosphoinositide 3-kinase (PI3K; 1:1,000, Cell Signaling Technology, Danvers, MA, USA), Akt ${ }^{\mathrm{p}-\mathrm{Thr} 308}(1: 1,000$, 
A

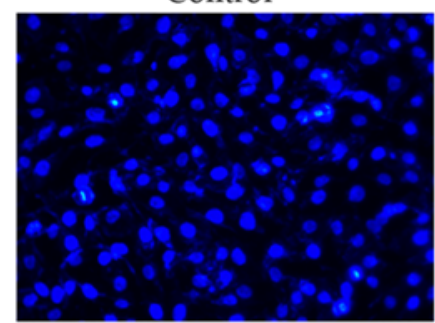

$50 \mu \mathrm{M}$
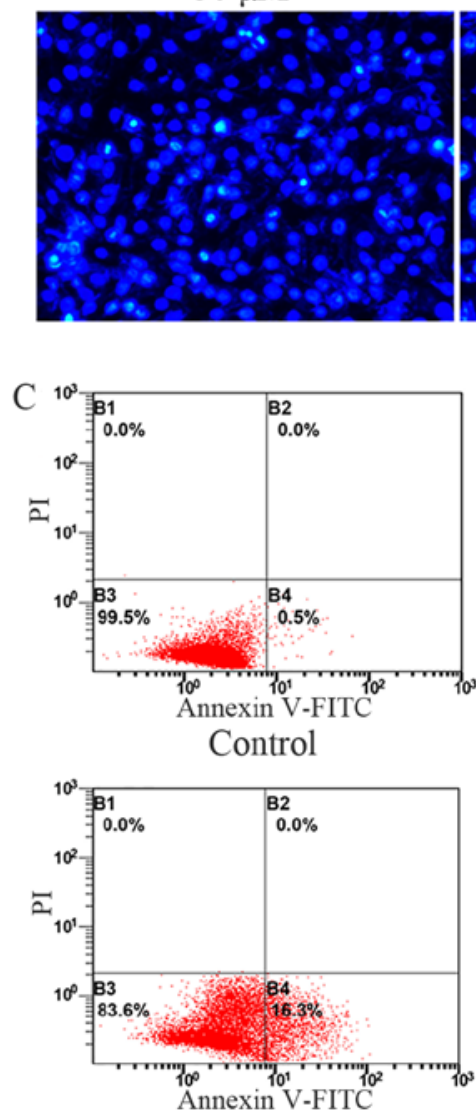

$50 \mu \mathrm{M}$

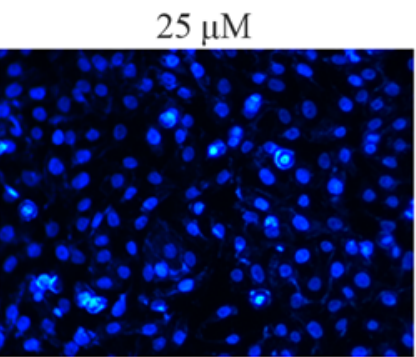

$100 \mu \mathrm{M}$
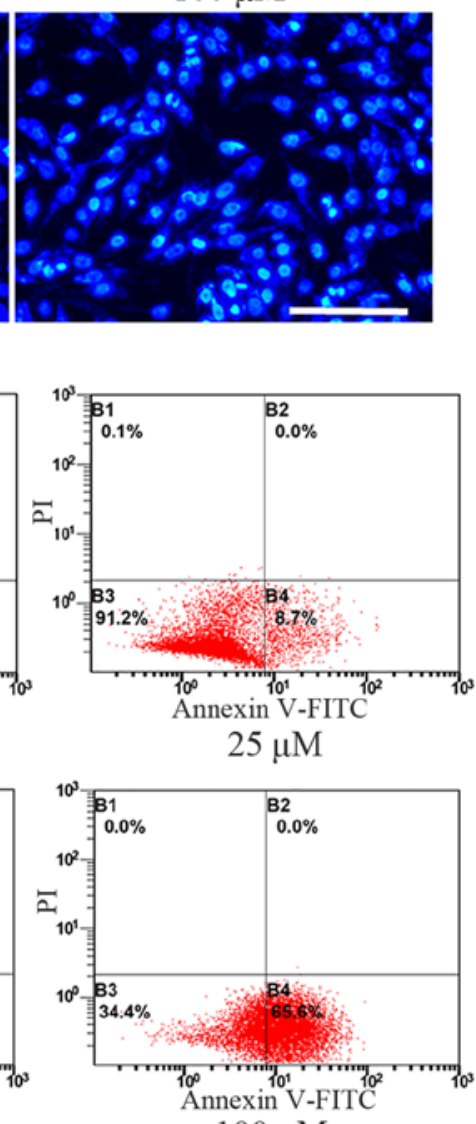

$100 \mu \mathrm{M}$

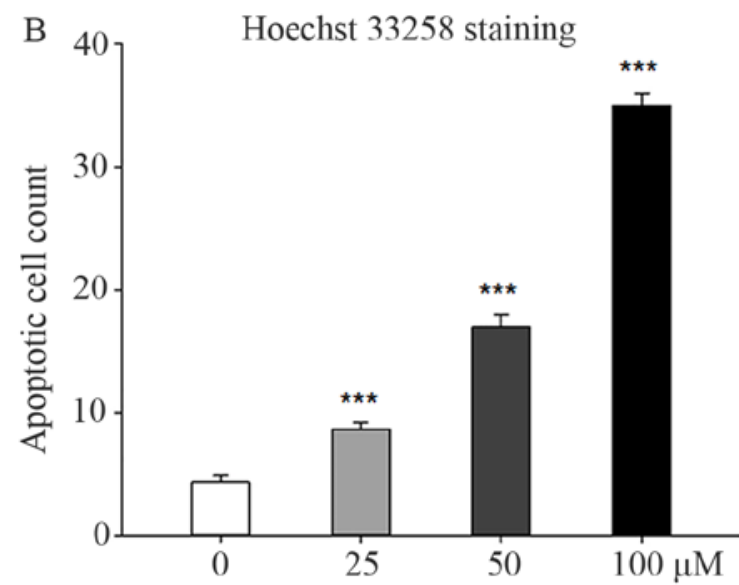

D $\quad$ Flow cytometry

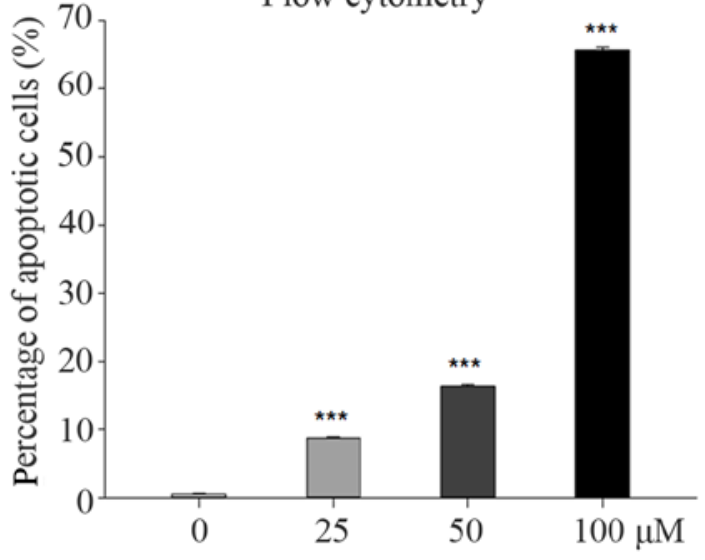

Figure 2. Enhanced apoptosis of osteosarcoma cells by galangin. (A) Hoechst 33258 staining of MG63 cells treated for 48 h with galangin concentrations of $0,25,50$, or $100 \mu \mathrm{M}$. Images were taken under a fluorescence microscope. Scale bar, $50 \mu \mathrm{m}$. (B) Results of counting stained dead cells. Data are presented as the mean $\pm \mathrm{SD} .{ }^{* * *} \mathrm{P}<0.001$ versus the control group. (C) Flow cytometry analysis of MG63 cells treated with galangin for $24 \mathrm{~h}$ at concentrations of $0,25,50$, or $100 \mu \mathrm{M}$. Annexin $\mathrm{V}(+) / \mathrm{PI}(-)$ cells were considered early apoptotic cells. (D) Quantitative analysis of flow cytometry. Data are presented as the mean \pm SD.

${ }^{* * *} \mathrm{P}<0.001$ versus the control group.

Abcam, Cambridge, UK), Akt (1:1,000, Abcam), cyclin D1 (1:1,000, Proteintech, Rosemont, IL, USA), p27 ${ }^{\text {Kipl }}(1: 1,000$, Proteintech), caspase-3 (1:5,000, Abcam) or caspase- 8 (1:5,000, Abcam), matrix metalloproteinase 2 (MMP-2; 1:1,000, Abcam), matrix metalloproteinase 9 (MMP-9; $1: 1,000$, Proteintech), and $\beta$-tubulin $(1: 1,000$, Bioworld Technology Inc., St. Louis Park, MN, USA).

Statistics. All data are presented as the mean \pm SD. The statistical significance was evaluated by one-way analysis of variance (ANOVA) methodology for repeated measurement, followed by Student-Newman-Keuls test. $\mathrm{P}<0.05, \mathrm{P}<0.01$ and $\mathrm{P}<0.001$ were considered to be statistically significant. SPSS software version 19.0 was used for the statistical analyses. All experiments were conducted in triplicates.

\section{Results}

Galangin inhibits the proliferation and cell cycle of osteosarcoma cells. Galangin significantly inhibited the proliferation of MG63 and U20S cells in a dose-dependent manner. The optical density (OD) value of MG63 cells remained stable in the 5,10 , and $25 \mu \mathrm{M}$ galangin treatment groups and was equivalent to the value of $0.83 \pm 0.063$ in the control group (Fig. 1B). However, the OD value dropped to $0.72 \pm 0.038$ in the $50 \mu \mathrm{M}$-group $(\mathrm{P}=0.034)$ and markedly dropped to $0.67 \pm 0.040$ in the $100 \mu \mathrm{M}$ group $(\mathrm{P}<0.001), 0.40 \pm 0.051$ in the $200 \mu \mathrm{M}$ group $(\mathrm{P}<0.001)$, and $0.35 \pm 0.015$ in the $300 \mu \mathrm{M}$ group $(\mathrm{P}<0.001)$. Similar trends were observed in U20S cells. The $\mathrm{IC}_{50}$ of galangin to MG63 and U20S cells $48 \mathrm{~h}$ post-treatment were determined as 234.8 and $227.0 \mu \mathrm{M}$, respectively. 

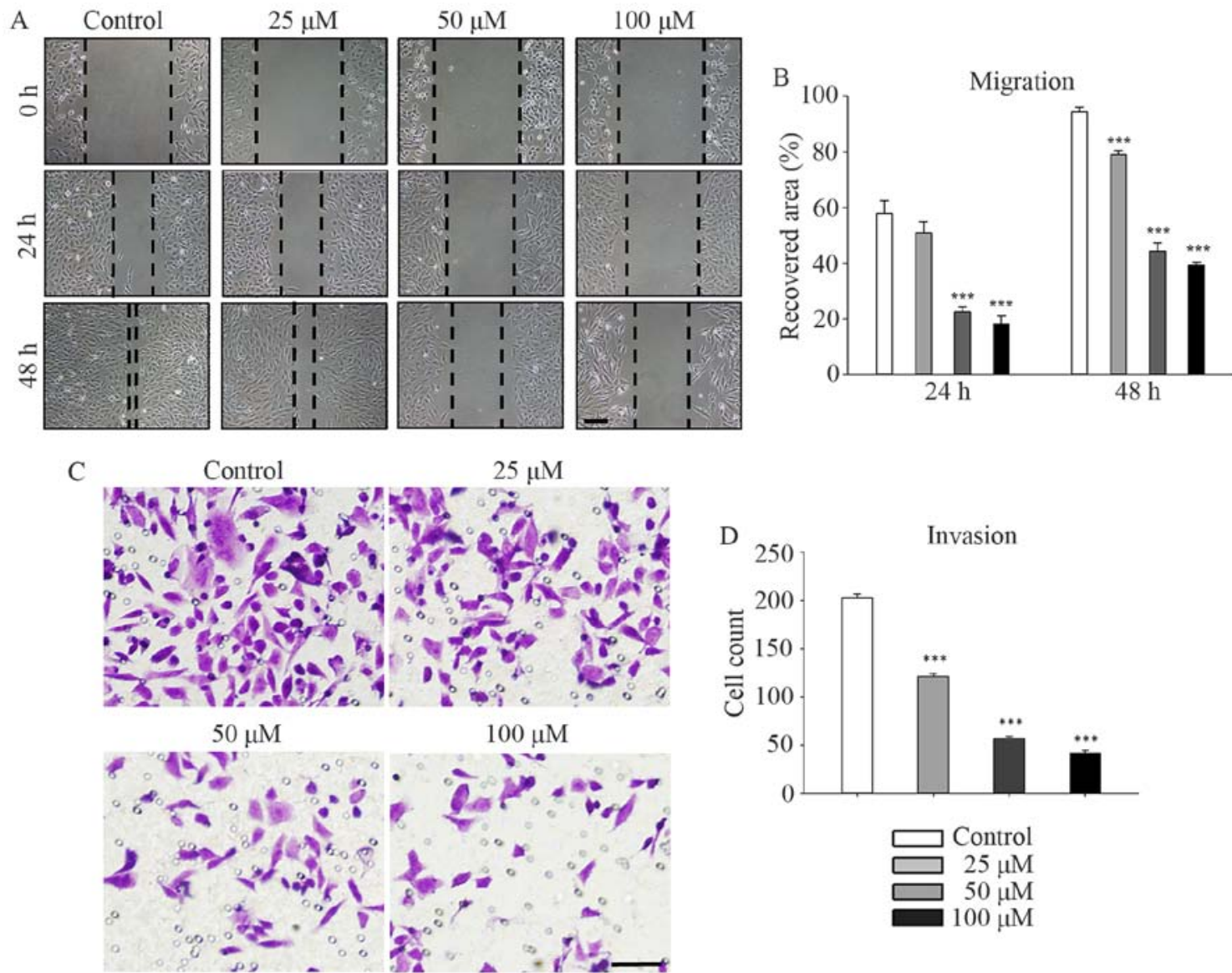

Figure 3. Inhibition of the migration and invasion of osteosarcoma cells by galangin. (A) MG63 cells were treated with galangin for 24 and $48 \mathrm{~h}$ at a concentration of 0, 25, 50, or $100 \mu \mathrm{M}$. Images were taken under a fluorescence microscope. Scale bar, $100 \mu \mathrm{m}$. (B) Quantitative analysis of the scratch-wound assay. (C) Images of invasion of MG63 cells treated with or without the indicated concentrations of galangin for $48 \mathrm{~h}$. Scale bar, $100 \mu \mathrm{m}$. (D) Count of invaded cells from the Transwell assay. Data are presented as the mean $\pm \mathrm{SD}$. ${ }^{* * *} \mathrm{P}<0.001$ versus the control group.

MG63 cells were seeded at the same density in 6-well plates and treated with galangin at concentrations of $0,25,50$, and $100 \mu \mathrm{M}$ for $48 \mathrm{~h}$. Images taken using an inverted phase contrast microscope showed a slight decrease in cultured cell numbers in the $25 \mu \mathrm{M}$ galangin group compared to those in the control group, and significantly reduced cell numbers at the 50 and $100 \mu \mathrm{M}$ galangin concentrations (Fig. 1C).

Galangin accelerated apoptosis in osteosarcoma cells. Galangin treatment significantly enhanced apoptosis in MG63 cells. The nucleus stained brilliant blue upon Hoechst 33258 staining, indicating condensed chromatin (Fig. 2A). The number of apoptotic MG63 cells observed under fluorescence microscopy increased to $8.6 \pm 0.57(\mathrm{P}<0.001), 17.0 \pm 1.00$ $(\mathrm{P}<0.001)$, and $35.0 \pm 1.00(\mathrm{P}<0.001)$ in the 25,50 , and $100 \mu \mathrm{M}$ groups, respectively, compared to $4.3 \pm 0.57$ in the control group (Fig. 2B). Similar trends were observed in the flow cytometry results. The percentages of early apoptotic cells increased to $8.7 \pm 0.20 \%(\mathrm{P}<0.001), 16.3 \pm 0.26 \%(\mathrm{P}<0.001)$, and $65.6 \pm 0.44 \%$ $(\mathrm{P}<0.001)$ in the 25,50 , and $100 \mu \mathrm{M}$ groups, respectively, compared to $0.5 \pm 0.10 \%$ in the control group (Fig. $2 \mathrm{C}$ and D).

Galangin suppresses the migration and invasion of osteosarcoma cells. Galangin markedly suppressed the migration and invasion of MG63 cells in a concentration-dependent manner. MG63 cells were treated with galangin at concentrations of 0 ,
25,50 , and $100 \mu \mathrm{M}$ and subjected to a scratch-wound assay (Fig. 3A and B). After incubation for $48 \mathrm{~h}$, the recovered area decreased to $78.5 \pm 1.5 \%(\mathrm{P}<0.001), 44.3 \pm 3.0 \%(\mathrm{P}<0.001)$, and $38.8 \pm 1.1 \%(\mathrm{P}<0.001)$ of its original size in the 25,50 , and $100 \mu \mathrm{M}$ groups, respectively, compared to $93.9 \pm 1.5 \%$ in the control group. Similar trends were observed at the 24-h time point. Transwell assays were performed to evaluate the inhibitory effect of galangin on the invasion of MG63 cells. The numbers of invading cells counted in the microscope images (Fig. 3C and D) were reduced to 121.3 $\pm 2.5(\mathrm{P}<0.001), 57.0 \pm 2.0$ $(\mathrm{P}<0.001)$, and $41.7 \pm 2.5(\mathrm{P}<0.001)$ in the 25,50 , and $100 \mu \mathrm{M}$ groups, respectively, compared to $203.3 \pm 3.5$ invading cells in the control group.

Galangin regulated PI3K and its downstream signaling pathway. Galangin markedly downregulated the protein levels of PI3K and $\mathrm{Akt}^{\mathrm{p}-\mathrm{Th} 308}$ in a concentration-dependent manner, while total Akt expression remained stable (Fig. 4A and B). We subsequently measured the effects of galangin on the protein expression of cyclin D1 and p27 ${ }^{\mathrm{Kipl}}$, which regulates G1 and S phase entry. The results showed that galangin treatment decreased cyclin D1 expression and increased p27 $7^{\text {Kip } 1}$ expression in a dose-dependent manner (Fig. 4C and D). The expression levels of caspase- 3 and caspase- 8 were significantly upregulated in galangin-treated MG63 cells (Fig. 4E and F). However, the expression levels of MMP-2 and MMP-9 were 

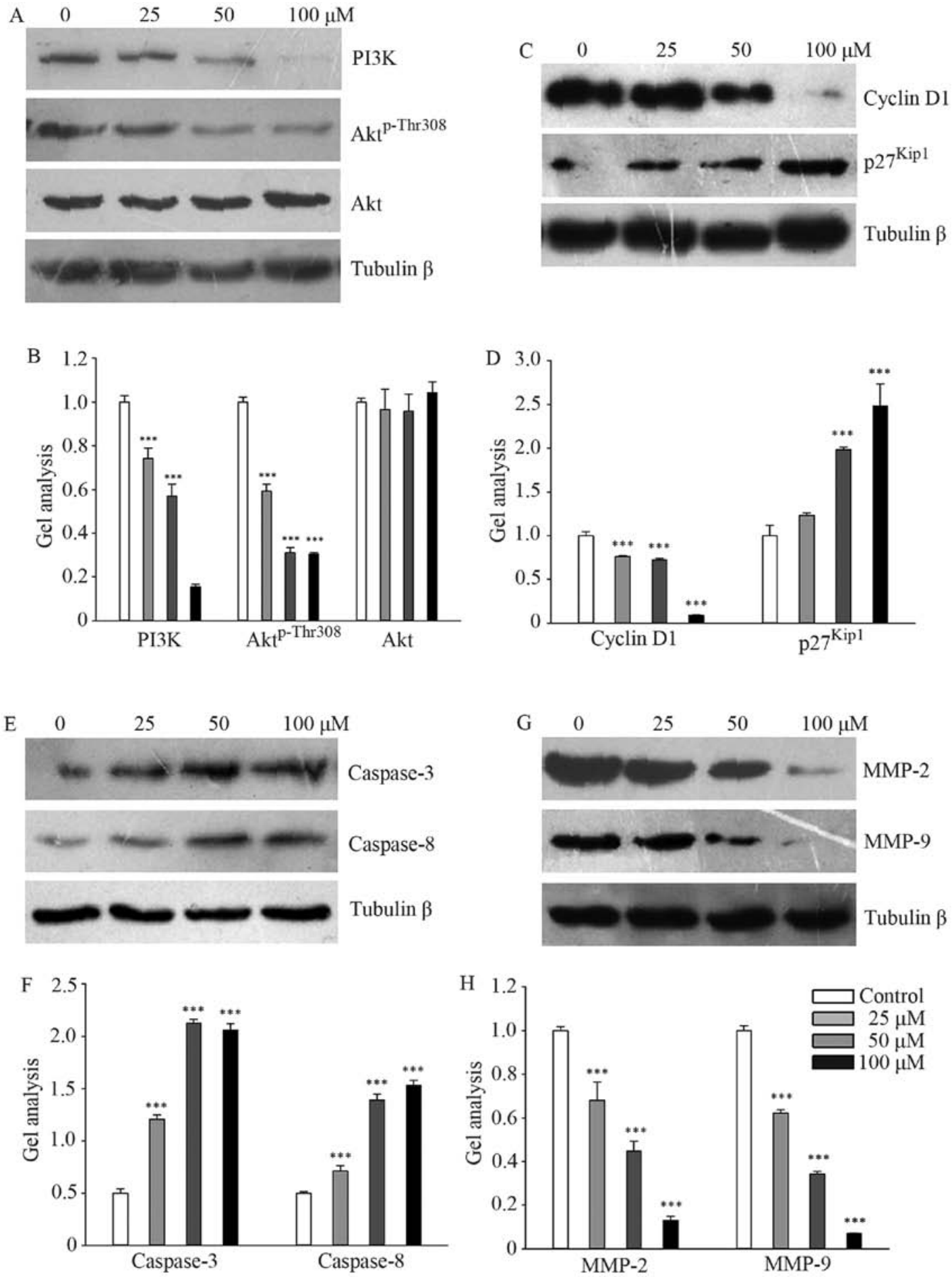

Figure 4. PI3K and its downstream signaling pathway targeted by galangin. (A, C, E and G) MG63 cells were treated with galangin for $48 \mathrm{~h}$ at a concentration of $0,25,50$, or $100 \mu \mathrm{M}$, and the levels of PI3K, Akt ${ }^{\mathrm{p}-\mathrm{Th} r 308}$, Akt, cyclin D1, p2 $7^{\mathrm{Kip} 1}$, caspase-3, caspase-8, MMP-2, and MMP-9 were analyzed by western blotting. $\beta$-tubulin was used as a loading control. (B, D, F and H) Quantitative analyses of the western blotting. Data are presented as the mean \pm SD. ${ }^{* * *} \mathrm{P}<0.001$ versus the control group.

significantly suppressed in galangin-treated MG63 cells (Fig. 4G and H).

\section{Discussion}

Galangin, a compound extracted from herb medicine, has been reported as an effective antitumor agent. It inhibits cell proliferation and induces apoptosis in several cancer cell lines, such a renal cell (18) and human colon cancer (19). Our data showed that the OD values of cultured osteosarcoma cells dropped significantly after exposure to galangin, and the apoptotic rates of cells significantly increased with galangin treatment. The migratory and invasive abilities of cells also significantly decreased after galangin treatment, which were accompanied by reduced protein expression of PI3K, $\mathrm{Akt}^{\mathrm{p} \text {-Thr308 }}$, cyclin D1, and MMP-2/9 and upregulation of $\mathrm{p} 27^{\mathrm{Kip} 1}$, caspase-3, 


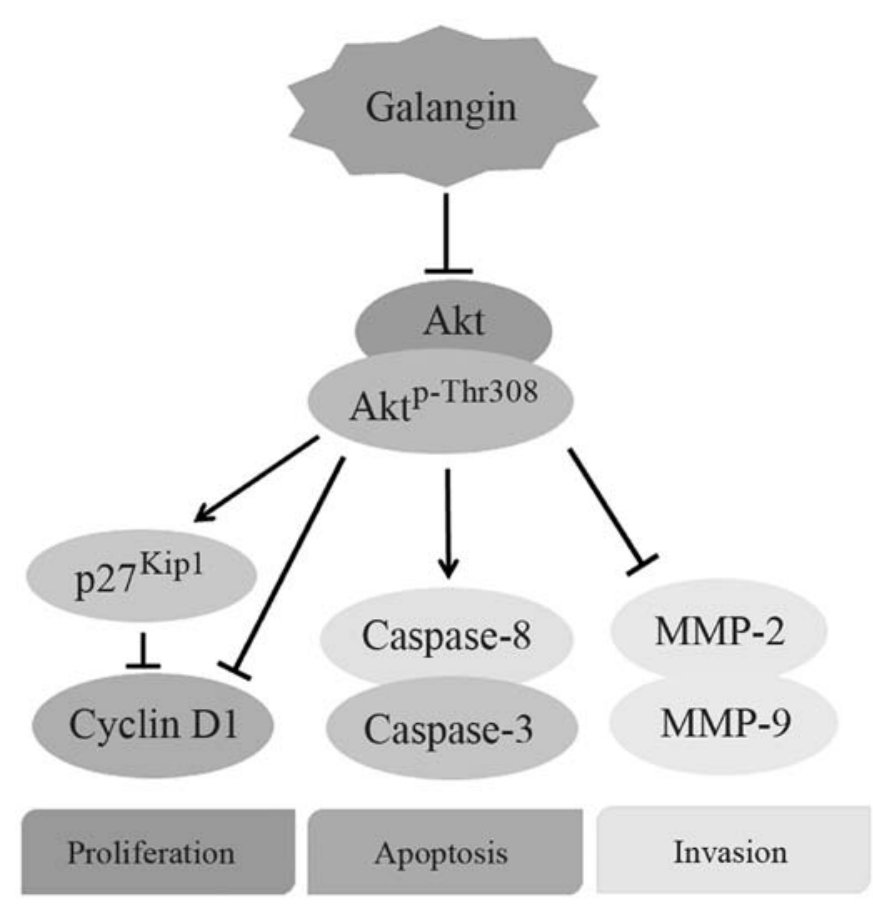

Figure 5. Suppression of proliferation and invasion and enhanced apoptosis of osteosarcoma cells by inhibition of PI3K and its downstream signaling pathway by galangin.

and caspase- 8 . The results suggest that galangin suppressed the proliferation and metastasis of osteosarcoma cells in a concentration-dependent manner, and the underlying mechanism is associated with inhibition of PI3K and its downstream signaling pathway (Fig. 5).

Galangin promotes apoptosis and inhibits proliferation of osteosarcoma cells. Our data showed that galangin inhibited the proliferation of osteosarcoma cells, rather than MC3T3-E1 cells, in a dose-dependent manner, indicating that galangin may be a tumor-targeted agent. The PI3K/Akt signaling pathway plays a key role in the regulation of cellular functions, and $\mathrm{PI} 3 \mathrm{~K}$ is activated largely in tumor cells than in non-malignant cells (20). The protein expression of PI3K in osteosarcoma cells was found to be significantly reduced by galangin treatment in the present study. These findings indicate that galangin may target osteosarcoma cells by reducing PI3K expression and exhibit little toxicity toward non-malignant cells. Both caspase-3 and caspase-8, proteases involved in extrinsic apoptosis, were activated after neoadjuvant chemotherapy to elicit cell death (21).

We also found that apoptosis in MG63 cells was enhanced significantly after galangin treatment, which was accompanied by increased protein expression levels of caspase- 8 and caspase-3. These results indicate that galangin may work as a caspase agonist in tumor cells, and may represent an alternative remedy for tumors. Moreover, we found that galangin markedly reduced the protein expression of cyclin D1, a key regulator that promotes the transition of cells from G1 phase to S phase, where rapid DNA synthesis occur (22). This may explain why galangin inhibits the proliferation of osteosarcoma cells. Similarly, a previous study reported that galangin induces significant cell cycle arrest of the human head and neck squamous carcinoma cells at the G0/G1 phase, with decreased expression of cyclin D1 (16), indicating that galangin mediates the cell cycle through the PI3K/Akt/ cyclin D1 signaling pathway.

In addition to the effect on cell proliferation, galangin was further found to inhibit cell migration and invade osteosarcoma cells. Efficient inhibition of tumor metastasis plays a particularly crucial role in improving the prognosis of patients with osteosarcoma because metastasis tends to occur at an early stage of the disease. In the present study, we demonstrated using Transwell assay that galangin treatment significantly reduces the migration and invasion of MG63 cells, accompanied by downregulation of protein expression levels of MMP-2 and MMP-9. Consistent with these findings, a previous study showed that galangin dose-dependently reduced the mRNA and protein expression levels of MMP-2 and MMP-9 in liver cancer HepG2 cells (23). These findings suggested that galangin could be used as an antimetastatic agent. Based on the downregulation of both PI3K and $\mathrm{Akt}^{\mathrm{p} \text {-Thr308 }}$, we deduce that galangin prevents the metastasis of osteosarcoma by inhibiting the PI3K/Akt/MMP-2/MMP-9 signaling pathway.

Our study has several limitations. First, the pharmacokinetic parameters of galangin remained to be unambiguously elucidated. Previous studies showed that the oral bioavailability of galangin was very low because it changed to glucuronidated forms after hepatic metabolism $(24,25)$. The intravenous administration or molecular chemical modification may improve its efficiency in vivo. Second, animal models to evaluate the galangin antitumor effects in vivo of osteosarcoma are required in the future. The effective concentration of galangin in vivo remained undetected. Therefore, physiologically relevant and attainable concentrations of galangin in animal model need to be further explored.

In conclusion, our data established the properties of galangin suppressing the proliferation, migration, and invasion of osteosarcoma cells, while enhancing its apoptosis. These effects occur at least through the inhibition of PI3K and its downstream signaling pathway. The results presented in our study may broaden the potential application of galangin, and may offer a promising therapeutic strategy for antiosteosarcoma therapy.

\section{Acknowledgements}

This study was supported by the Natural Science Foundation of Zhejiang Province (LQ16H160013 and LY15H060005) and the National Natural Science Foundation of China (81572126).

\section{References}

1. Picci P: Osteosarcoma (osteogenic sarcoma). Orphanet J Rare Dis 2: 6, 2007.

2. Chou AJ, Geller DS and Gorlick R: Therapy for osteosarcoma: Where do we go from here? Paediatr Drugs 10: 315-327, 2008.

3. Yu C and Wang W: Relationship between 15 gene mutation and formation and metastasis of malignant osteosarcoma. Med Sci Monit 22: 656-661, 2016.

4. Allison DC, Carney SC, Ahlmann ER, Hendifar A, Chawla S, Fedenko A, Angeles C and Menendez LR: A meta-analysis of osteosarcoma outcomes in the modern medical era. Sarcoma 2012: 704872, 2012.

5. Robl B, Pauli C, Botter SM, Bode-Lesniewska B and Fuchs B: Prognostic value of tumor suppressors in osteosarcoma before and after neoadjuvant chemotherapy. BMC Cancer 15: 379, 2015. 
6. Guo W, Healey JH, Meyers PA, Ladanyi M,Huvos AG, Bertino JR and Gorlick R: Mechanisms of methotrexate resistance in osteosarcoma. Clin Cancer Res 5: 621-627, 1999.

7. Zhang Z, Zhang Y, Lv J and Wang J: The survivin suppressant YM155 reverses doxorubicin resistance in osteosarcoma. Int J Clin Exp Med 8: 18032-18040, 2015.

8. Jung YC, Kim ME, Yoon JH, Park PR, Youn HY, Lee HW and Lee JS: Anti-inflammatory effects of galangin on lipopolysaccharide-activated macrophages via ERK and NF- $\kappa \mathrm{B}$ pathway regulation. Immunopharmacol Immunotoxicol 36: 426-432, 2014.

9. Zha WJ, Qian Y, Shen Y, Du Q, Chen FF, Wu ZZ, LI X and Huang M: Galangin abrogates ovalbumin-induced airway inflammation via negative regulation of NF-kappaB. Evid Based Complement Alternat Med 767689: 2013, 2013.

10. Cushnie TP and Lamb AJ: Assessment of the antibacterial activity of galangin against 4-quinolone resistant strains of Staphylococcus aureus. Phytomedicine 13: 187-191, 2006.

11. Pepeljnjak S and Kosalec I: Galangin expresses bactericidal activity against multiple-resistant bacteria: MRSA, Enterococcus spp. and Pseudomonas aeruginosa. FEMS Microbiol Lett 240: 111-116, 2004.

12. Meyer JJ, Afolayan AJ, Taylor MB and Erasmus D: Antiviral activity of galangin isolated from the aerial parts of Helichrysum aureonitens. J Ethnopharmacol 56: 165-169, 1997.

13. Han MA, Lee DH, Woo SM, Seo BR, Min KJ, Kim S, Park JW, Kim SH, Choi YH and Kwon TK: Galangin sensitizes TRAILinduced apoptosis through down-regulation of anti-apoptotic proteins in renal carcinoma Caki cells. Sci Rep 6: 18642, 2016

14. Su L, Chen X, Wu J, Lin B, Zhang H, Lan L and Luo H: Galangin inhibits proliferation of hepatocellular carcinoma cells by inducing endoplasmic reticulum stress. Food Chem Toxicol 62 810-816, 2013.

15. Choi YJ, Lee YH and Lee ST: Galangin and kaempferol suppress phorbol-12-myristate-13-acetate-induced matrix metalloproteinase-9 expression in human fibrosarcoma HT-1080 cells. Mol Cells 38: 151-155, 2015.
16. Zhu L, Luo Q, Bi J, Ding J, Ge S and Chen F: Galangin inhibits growth of human head and neck squamous carcinoma cells in vitro and in vivo. Chem Biol Interact 224: 149-156, 2014

17. Li X, Huang T, Jiang G, Gong W, Qian H and Zou C: Synergistic apoptotic effect of crocin and cisplatin on osteosarcoma cells via caspase induced apoptosis. Toxicol Lett 221: 197-204, 2013.

18. Cao J, Wang H, Chen F, Fang J, Xu A, Xi W, Zhang S, Wu G and Wang Z: Galangin inhibits cell invasion by suppressing the epithelial-mesenchymal transition and inducing apoptosis in renal cell carcinoma. Mol Med Rep 13: 4238-4244, 2016.

19. Ha TK, Kim ME, Yoon JH, Bae SJ, Yeom J and Lee JS: Galangin induces human colon cancer cell death via the mitochondrial dysfunction and caspase-dependent pathway. Exp Biol Med (Maywood) 238: 1047-1054, 2013.

20. Tian F, Ding D and Li D: Fangchinoline targets PI3K and suppresses PI3K/AKT signaling pathway in SGC7901 cells. Int J Oncol 46: 2355-2363, 2015.

21. Chen ZH and Feng B: Effect of the change of caspase-3 activity on the neoadjuvant chemotherapy-induced apoptosis of largeintestinal carcinoma cells. Hunan Yi Ke Da Xue Xue Bao 28 117-120, 2003 (in Chinese).

22. Resnitzky D and Reed SI: Different roles for cyclins D1 and E in regulation of the G1-to-S transition. Mol Cell Biol 15: 3463-3469, 1995.

23. Chien ST, Shi MD, Lee YC, Te CC and Shih YW: Galangin, a novel dietary flavonoid, attenuates metastatic feature via PKC/ERK signaling pathway in TPA-treated liver cancer HepG2 cells. Cancer Cell Int 15: 15, 2015.

24. Chen F, Tan YF, Li HL, Qin ZM, Cai HD, Lai WY, Zhang XP, Li YH, Guan WW, Li YB, et al: Differential systemic exposure to galangin after oral and intravenous administration to rats. Chem Cent J 9: 14, 2015.

25. Feng WH, Zhang HH, Zhang Y, Sun M and Niu JL: Determination of galangin in rat plasma by UPLC and pharmacokinetic study. J Chromatogr B Analyt Technol Biomed Life Sci 998-999: 26-30, 2015. 